\title{
La perspectiva fenomenológica en la Filosofía del Trabajo de Geörgy Lukács
}

Manuel Bonilla Bonilla

Universidad Luis Vargas Torres, Ecuador 


\title{
La perspectiva fenomenológica en la Filosofía del Trabajo de Geörgy Lukács*
}

Resumen: este artículo investiga el desarrollo, en la filosofía de Lukács, de una aproximación fenomenológica sobre el devenir de la conciencia histórica, la cual le permitió explicar diversos fenómenos contemporáneos como el de la alienación de la conciencia del individuo en el capitalismo avanzado. Describe la complementación que Lukács hizo de esta perspectiva por medio de la sistematización de las categorías ontológicas del trabajo.

Palabras clave: trabajo, fenomenología, ontología, conciencia, historia, reflejo.

\section{The phenomenological perspective in the \\ Philosophy of Labor of Geörgy Lukács}

\begin{abstract}
Lukács, of a phenomenological approach to the evolution of the historical consciousness, which allowed him to explain various contemporary phenomena such as the alienation of the consciousness in advanced capitalism. It describes the complementation that Lukács made of this perspective, with a further systematization of the ontological categories of labor.
\end{abstract}

Keywords: labor, phenomenology, ontology, conscience, history, reflection.

Fecha de recepción: 2 de febrero de 2019

Fecha de aceptación: 24 de abril de 2019

Forma de citar (APA): Bonilla, M. (2019). La perspectiva fenomenológica en la Filosofía del Trabajo de Geörgy Lukács. Revista Filosofía UIS, 18(2), doi: 10.18273/ revfil.v18n2-2019009

Forma de citar (Harvard): Bonilla, M. (2019). La perspectiva fenomenológica en la Filosofía del Trabajo de Geörgy Lukács. Revista Filosofía UIS, 18(2), 167-183.

Manuel Alejandro Bonilla Bonilla: ecuatoriano. Doctor en Filosofía, Universidad Nacional de La Plata. Profesor titular de la Universidad Luis Vargas Torres, Ecuador.

Correo electrónico: manuel.bonilla@utelvt.edu.ec

ORCID: 0000-0002-2334-9876

*Artículo de reflexión derivado de investigación. 


\section{La perspectiva fenomenológica en la Filosofía del Trabajo de Geörgy Lukács}

La actividad filosófica del Lukács tardío se caracteriza por el intento consciente de avanzar en la realización de proyectos sistemáticos de orientación marxista enfocados en áreas fundamentales de la filosofía. Lukács consideraba que la filosofía marxista era capaz de producir obras de carácter teórico que estuvieran en consonancia con los desarrollos filosóficos contenidos en la obra de Marx, y que, partiendo de ellos, discutieran los fundamentos de las distintas áreas del pensar y del actuar humanos. Teoría estética, ontología y ética, los tres campos tradicionales en los cuales se ocupó el Lukács del último periodo, y que dieron como resultado las obras sistemáticas de su etapa tardía (la Ontología del Ser Social, las dos obras sobre Estética, el proyecto inacabado de una Ética marxista), comparten el intento de establecer una fundamentación filosófica de la realidad social con un enfoque abarcativo y generalizador. Este carácter es tan pronunciado, que la época última del filósofo húngaro manifiesta una movilidad continua en el esfuerzo intelectual dedicado a estas respectivas áreas, y es que, de acuerdo con la visión filosófica del Lukács tardío, no sería posible establecer postulados filosóficos generales de una sin mencionar los postulados filosóficos generales de la otra. En particular, fue una perspectiva ontológica —el intento de hallar los fundamentos filosóficos de la realidad de acuerdo con categorías marxistas-, lo que motivó a que Lukács se sintiera confrontado con la tarea de abarcar sucesivamente al final de su vida la sistematización de cuestiones de carácter estético, ontológico y, por último, ético.

Sabemos que Lukács comprendía la Ontología del Ser Social como una forma de prolegómeno a problemas a ser tratados en una ética marxista posterior (Lukács, 1984, p. 664), y que, en el prefacio húngaro a la reedición de Mi camino hacia Marx, afirmó tácitamente que la estética es una parte orgánica de una más comprensiva ontología del ser social (Zoltai, 1993, p. 536). Esta íntima conexión de la primera parte de la estética, de la Ontología del Ser Social y de los esbozos sobre Ética, no existiría sin la "orientación social ontológica" (Benseler, 1986, p. 737) característica del filosofar del Lukács tardío y que hace posible contrastar y complementar los diferentes postulados ontológicos que se encuentran en los grandes proyectos sistemáticos de esta época. 
De acuerdo con Lukács, es la Ontología la que muestra los postulados filosóficos más generales sobre la realidad social, de modo que postulados de la ética y la estética "se encuadran" en el marco de una teoría ontológica fundamentada en el proceso dialéctico del trabajo. Por ejemplo, en la Ontología del Ser Social Lukács afirma que ciertas cuestiones como la relación entre racionalidad del ser social y sentido del ser humano - una importante cuestión ontológica-, solamente podrían ser estudiadas en el conjunto de relaciones dialécticas que rebasan la actividad social neutra, requiriendo unos análisis más específicos que debían ser abordados en una Ética que desvelara pertinentes categorías ontológicas (Lukács, 1984, p. 636). En el transcurso de estas investigaciones Lukács hizo notar que, aparte de la compresión general de la ontología, las categorías histórico-sociales que corresponden a la dimensión ontológica o estética tienen una concreción específica en cada momento del proceso social histórico; asimismo, reconoció la influencia de tal concreción histórica en el modo en que se articula cada objetividad en el marco de la realidad social. Es en este análisis de la forma en que las categorías ontológicas se realizan en el paso de la historia y, más particularmente, en el análisis de la forma como la conciencia histórica reacciona e influye en tal concreción, que Lukács recurre, como vamos a ver, a una particular forma de fenomenología. Para presentar la interacción entre la orientación ontológica y la fenomenológica en la filosofía del trabajo de Lukács, conviene distinguir en primer lugar aproximación fenomenológica y ontológica en su obra. El filósofo Infranca ha hecho aportes a esta cuestión en varios textos y artículos vinculados con el tema del marxismo lukácsiano (Infranca, 2007, pp. 263-308). Aunque la argumentación que Infranca hace sobre este punto ha despertado algunas reservas entre los estudiosos de la obra lukácsiana, a nuestro parecer él ha mostrado de manera convincente que los análisis de Historia y Consciencia de Clase - pese a la interpretación corriente entre los que, entusiastas de la obra juvenil, son críticos de la obra tardía-, no se encuentran en contradicción directa con los análisis de la Ontología del Ser Social'1. Obras anteriores de crítica filosófica han puesto de manifiesto correspondencias sensibles entre las investigaciones presentes en Historia y Consciencia de Clase y ciertas argumentaciones de la Ontología del Ser Social, pero Infranca ha comprobado que aquellas correspondencias manifiestas se deben especialmente al tratamiento del concepto de trabajo. El concepto de trabajo es abordado en cada obra respectiva mediante una aproximación metodológica distintiva, hecho significativo que produce, a la par que precisas correspondencias entre las obras, otras tantas diferencias en la argumentación y exposición. La dualidad de la aproximación al concepto de trabajo corresponde por un lado a la predominancia de una perspectiva fenomenológica —en Historia y Consciencia de Clase- y, por otro, a la existencia de una perspectiva ontológica —en Ontología del Ser Social—. Entre ambas metodologías el análisis

\footnotetext{
${ }^{1}$ Si bien, a lo largo de toda la obra madura de Lukács, en artículos y libros de filosofía y teoría política, se puede reconocer el debate crítico con varios postulados presentados en Historia y Consciencia de Clase (cfr. Breines, 1979, p. 535ss.).
} 
de textos comprueba una sucesión lógica, expresada en la sucesión cronológica real de los textos de Historia y Consciencia de Clase y de Ontología del Ser Social.

Como es sabido, un objeto central de la juvenil Historia y Consciencia de Clase es seguir, de modo materialista-histórico, la hegeliana "ciencia de la experiencia de la conciencia". Lukács tenía en ese entonces como pretensión el describir la génesis de la conciencia del proletariado sobre la base de un esquema filosófico e histórico recortado según el modelo de la Fenomenología del Espíritu, pero con un esquema en el que ya no es propiamente el despliegue de la autoconciencia - como en Hegel_-, sino el desarrollo dialéctico e inmanente de las categorías histórico-sociales lo que proporciona la movilidad al proceso. El movimiento dialéctico de las categorías, que se expresa siempre en una determinada "tendencia histórico social" colocada en relación reflexiva con la dinámica económicosocial de las sociedades, es asumido como el mecanismo central para reconstruir el devenir de las "formas de conciencia social". De acuerdo con Lukács, la conciencia de los individuos interviene en los momentos definitivos que llevan a la concretización objetiva de la categoría. Por ello el movimiento histórico de las categorías es el horizonte en el cual se enmarcan últimamente los cambios de la conciencia histórica de los pueblos y los grupos sociales. En Historia y Consciencia de Clase Lukács se ocupó de investigar la conexión de la conciencia individual e intersubjetiva con marco de la totalidad procesual que corresponde a la sociedad capitalista, en razón de que tal relación constituiría — según el esquema tomado de la Fenomenología del Espíritu — la figura de la conciencia histórica más reciente del individuo moderno.

En los análisis y distintas argumentaciones acerca de la relación concienciamundo en el capitalismo, Lukács manifiesta la importancia central de la categoría social de cosificación (Verdinglichung)². De acuerdo con Lukács, en la evolución histórica de las relaciones económico-sociales, los intercambios entre los individuos que toman la forma de relaciones sociales cosificadoras adquieren un rol predominante en la marcha conjunta de la sociedad y en la génesis de las distintas formas de conciencia social. Estudiando el fenómeno social de cosificación, Lukács descubre que la génesis de la conciencia del proletariado sigue a la estructura del proceso del trabajo extrañador que asimila el obrero con el objeto del trabajo producido; lo cual quiere decir que la vida del obrero se halla atravesada por el carácter fetichista de la mercancía que media todo el proceso de producción y distribución en el capitalismo. La influencia de la relación inmediata

\footnotetext{
${ }^{2}$ Término que en la tradición marxista proviene de Hegel, quien en la Fenomenología del Espíritu la introduce como expresión de la auto-exteriorización del sujeto en una "forma concreta" exterior. En Marx designa un momento del proceso de la fetichización de la mercancía, en el que las relaciones sociales que se encuentran tras las categorías económicas son tomadas como cosas, así, por ejemplo, las nociones abstractas de propiedad y de trabajo (cfr. Marx, 1972, pp. 7-11). En Lukács tal categoría expresa aquellas relaciones en las que la alienación de la conciencia individual asume la apariencia de cosa dada y universal.
} 
que la conciencia del trabajador tiene con las determinaciones categoriales propias del trabajo abstracto y enajenado, determina que sea el obrero el que exprese la relación de la conciencia que es más directa, fecunda e indefinida con respecto del objeto producido en la industria y que, por tanto, sea él el más adecuado para mover esta relación a una etapa superior en la relación dialéctica.

Los numerosos e intensivos análisis que Lukács lleva a cabo para sostener la predominancia de las categorías de cosificación y extrañamiento en el proceso de trabajo, y las consecuencias que esto tiene para el devenir de las tendencias histórico sociales del capitalismo avanzado, constituyen la parte central del texto de Historia y Consciencia de Clase. Aquí nos limitamos a señalar que el análisis de la génesis de la conciencia del obrero a través de la estructura del trabajo extrañador supone, primero, la postulación de una fenomenología de la experiencia de la conciencia; la cual se encuentra abocada a un análisis de las condiciones concretas y actuales en que tal proceso cosificador se realiza; segundo, que tal fenomenología, al igual que la fenomenología hegeliana, presupone la emergencia de una dimensión estrictamente ontológica, aun cuando se esfuerza por moverse a partir del inmediato e histórico ser-precisamente-así del proceso de trabajo (cfr. Infranca, 2007, pp. 153-154). El principal elemento de la dimensión ontológica presente en Historia y Consciencia de Clase es el papel que la actividad productiva tiene en la articulación de las categorías histórico sociales, y con ello, en la estructuración de la totalidad procesual que es cada sociedad en una etapa histórica. En Historia y Consciencia de Clase la significación ontológica presente en el trabajo está supuesta en los distintos análisis de detalle que manifiestan la forma en que la contemporánea figura de la conciencia del capitalismo avanzado — aquella correspondiente al obrero alienado— refleja la dialéctica histórico social del proceso del trabajo. La argumentación fenomenológica que allí se lleva a cabo es necesaria por ser un paso lógicamente anterior a la argumentación ontológica, encargado de encontrar cuáles son las categorías ontológicas operativas en los hechos sociales de enajenación. La dialéctica de esencia y fenómeno que se encuentra en Hegel y en Marx asume que las determinaciones más inmediatas son un primer estadio del camino que la conciencia recorre hasta la captación del amplio complejo de determinaciones que se cristaliza en cada fenómeno social y la comprensión de las determinaciones esenciales. Por tanto, no sería posible obtener un diagnóstico adecuado de las determinaciones del ser social, si antes no se han estudiado y estructurado las determinaciones que ejercen una influencia más directa e inmediata en el medio aparencial en el que se desenvuelve la conciencia. El paso desde la apariencia fenoménica para la conciencia hasta la esencia de lógica de los hechos y hasta la totalidad procesual es lo que asegura la pertinencia de la argumentación ontológica. Únicamente después de haberse dado tal paso es fundamentado el estudio de las determinaciones ontológicas del ser social. El variado cuadro de mediaciones que intervienen en la dinámica de la consciencia con la categoría de trabajo se encuentra todavía presente en el Lukács de la Ontología del ser social, solo que, en rigor, en calidad de presupuesto, de tal 
modo que la teoría del ser social puede especificar en el trabajo, y sin ulteriores reconstrucciones, el punto de partida adecuado para una exposición ontológica de su objeto (cfr. Infranca, 2007, p. 154) ${ }^{3}$.

El análisis de los textos muestra cómo la diferencia de aproximación hacia los hechos produce resultados diferentes en la exposición y la argumentación. En particular, no se encuentra en Historia y Consciencia de Clase el análisis ontológico-genético del trabajo que se lleva a cabo en el texto de la Ontología del Ser Social, por lo que el fenómeno de la extrañación solo es abordado en su "dimensión subjetiva", dejando de lado los diferentes espacios de la realidad social que tienen su génesis en la objetivación de la esencia genérica y la influencia que esto tiene en las categorías del Ser Social; hecho que hace que el mismo fenómeno de la extrañación solo sea comprendido limitadamente. A estas limitaciones de una aproximación fenomenológica que carece de fundamentos categoriales ontológicos se refería Lukács cuando criticó la conceptualización de la objetivación que se encuentra presente en Historia y Consciencia de Clase:

Si se considera que lo que es objeto de la praxis, y por ende el propio trabajo, sobre todo, es una objetivación [...] que los pensamientos, los sentimientos humanos, son objetivados, etc., entonces es evidente que estamos frente a una forma universalmente humana de las relaciones de los hombres entre sí. Sólo cuando las formas objetivadas en la sociedad reciben funciones que ponen la esencia del hombre en conflicto con su ser, sólo entonces surge la relación objetivamente social de enajenación [...] En Historia y conciencia de clase no reconocí esta dualidad (Lukács, 1968, p. 21).

Historia y Consciencia de Clase puede ser leída, por tanto, en orden a completarla cabalmente, a precisarla y a reformarla, como un capítulo antecedente y seminal de la Ontología del Ser Social. Al respecto podría pensarse en la relación que existe entre la Fenomenología del Ser Social y la Ciencia de la Lógica hegelianas. Al igual que la Fenomenología del Espíritu, Historia y Consciencia de Clase ofrece, operando en concretos momentos históricos, el movimiento dialéctico inmanente de nociones y categorías en el trasfondo del desarrollo de las formas de la conciencia; mientras que en la Ciencia de la Lógica los conceptos son más que nada expuestos, suponiendo ya un movimiento histórico concreto que no es el centro de la argumentación, que asume allí un punto de vista analítico y generalizador, algo semejante a lo que ocurre en la Ontología del Ser Social. Pero mientras que la Fenomenología del Espíritu podría ser subsumida como momento del sistema de la filosofía hegeliana —recordemos que Hegel la incorpora como capítulo de la Enciclopedia de las Ciencias Filosóficas-, el enfoque subjetivo sobre

\footnotetext{
${ }^{3}$ Se comprueba así la estructura de una recursividad hermenéutica entre los momentos fenomenológicos y ontológicos de la investigación filosófica, que son resaltados de acuerdo con el horizonte de cuestiones presentes en cada obra. Sin embargo, una primera investigación exhaustiva fenomenológica (Historia y Consciencia de Clase) era necesaria antes de una investigación exhaustiva ontológica (Ontología del Ser Social).
} 
el fenómeno de la extrañación propio de Historia y Consciencia de Clase, que se centra unilateralmente en las condiciones subjetivas del proceso social que justifica la cosificación, hace que los postulados de aquella siempre deban ser contrastados con la perspectiva más objetivista y abarcante de la Ontología del Ser Social. La argumentación lukácsiana presente en esta obra está en directa vinculación con los análisis de la crítica de economía política realizados por Marx, en especial con los que, en los Manuscritos filosóficos del 44, discuten la relación del pensamiento con la realidad y la importancia de la categoría de trabajo en esta relación (cfr. Marx, 1968, pp. 22-27).

Según la argumentación seguida por Marx en su crítica de economía política, el pensamiento es caracterizado por su orientación hacia lo real material; en un proceso que lleva al establecimiento de conceptos que permitan la realización de la praxis según fines concretos. La producción espontánea de pensamientos en el contacto del hombre con su entorno material es, según Marx, un momento de la relación general del hombre con la realidad; un momento primitivo de la conciencia, que corresponde a la vida cotidiana del hombre en sus labores habituales de producción y reproducción de la vida. La espontaneidad del proceso implica una directa relación con las determinaciones materiales de la existencia, que hace que la conciencia lleve a cabo un proceso de abstracción que crea conceptos significativamente influenciados por determinaciones de las categorías económico-sociales. Marx argumenta que, en comparación con el "método" que en la crítica de economía política permite encontrar la dialecticidad de la relación entre categorías sociales, el saber de la vida cotidiana conserva más profundamente la huella de las determinaciones que están inmediatamente presentes en las categorías y se ocupa menos del complejo de las relaciones entre ellas. En la crítica de economía política llevada a cabo en El Capital, Marx argumentó la gran influencia que alcanzan las determinaciones de la vida económica moderna en la vida práctica, de manera que los conceptos de los individuos expresan con facilidad las determinaciones económicas en su inmediatez:

Las representaciones de un comerciante, especulador de bolsa, banquero, son necesariamente invertidas. Aquellas representaciones del fabricante son falsificadas por intermedio de los procesos de circulación de mercancías, en las cuales ha invertido su capital, o por la equiparación de las tasas de las ganancias. Categorías como las de competencia desempeñan en la cabeza de aquellos un rol completamente invertido (Marx, 1968, p. 325) ${ }^{4}$.

De acuerdo con Marx, este proceso sucede porque las determinaciones de las categorías económicas, como las de circulación, capital, etcétera, están consideradas en su inmediata movilidad y en buena parte aisladas de sus relaciones complementarias con el todo unitario de la producción, de manera que, por

\footnotetext{
${ }^{4}$ En adelante, toda traducción de Marx o Lukács es hecha por el autor del artículo a partir de la versión en alemán.
} 
ejemplo, en la mente del especulador de bolsa el fenómeno de circulación del dinero y del alza y baja de divisas es fenómeno que sigue reglas inmanentes y casi esotéricas. En tales casos los hombres juzgan respecto de su realidad económica en una relación acrítica con las determinaciones que intervienen en la específica parcela de que se ocupan, de modo que en su cabeza el verdadero rol de las categorías aparece invertido, tomándose los efectos por las causas.

Cuando en el acto de la producción los sujetos económicos toman conciencia de las categorías económicas, se hace presente la apariencia de movimiento de aquellas categorías, y no el movimiento interno y real que es presentado por la crítica de economía política marxiana. Esto sucede cuando el individuo juzga su realidad en tanto banquero, especulador de bolsa, capitalista, y demás roles semejantes, instancias de su vivir en que tiene una relación más espontánea con el proceso productivo, de distribución o de consumo.

En los textos de crítica de economía política de Marx tal acontecer es entendido como resultado de la influencia de la fetichización de la mercancía y el concepto de cosificación asociado a ella. Lukács desarrolla esta argumentación y ofrece sus propias definiciones respecto a los conceptos involucrados en el proceso de inversión y deformación ideológica que fue presentado por Marx 5 . En Ontología del Ser Social, el escrito lukácsiano donde más exhaustivamente están las bases ontológicas de este fenómeno, la cosificación se entiende en líneas generales como elemento del esquema conceptual formado por los procesos de objetivación (Vergegenständlichung) y de enajenación (Entäusserung) de la genericidad (Gattungsmäßigkeit) humana por parte del individuo concreto.

De acuerdo con Lukács, ambos conceptos son considerados factores fundamentales del proceso histórico de autoconstitución del hombre en la historia; por medio de la transformación de la naturaleza y de lo real-social, y por la construcción cada vez más compleja de un mundo objetivo social resultado de la actividad del trabajo (cfr. Fortes, 2012, p. 70). La categoría de objetivación expresa el conjunto de determinaciones objetivas que son el resultado de la continua construcción y ampliación objetiva de la capacidad humana de transformar la naturaleza y el mundo social, y, por tanto, de crear las propias condiciones de su existencia. La categoría de enajenación indica las determinaciones que corresponden al fenómeno general de que, siempre que transforma la naturaleza y el mundo social, el hombre lleva a cabo la adecuación de su subjetividad interior a las condiciones exteriores del proceso productivo. De ese modo, Lukács entiende que el hombre crea objetividades sociales cada vez más complejas según se desarrollan las fuerzas sociales productivas, y que, en ese proceso, transforma su propia subjetividad —enajena sus facultades intelectuales,

${ }^{5}$ Estudio en profundidad sobre los conceptos de objetivación y alienación en la obra de Marx se encuentra en Mészáros (2009). 
emocionales y físicas - con base en las objetividades existentes y aquellas que se busca transformar y/o crear según cada particular articulación de reflejo y posición teleológica. En otras palabras, la pareja objetivación/enajenación revela que el hombre, en tanto sujeto, objetiva permanentemente su mundo social al mismo tiempo que transforma continuamente su propia naturaleza de "sujeto colocador de objetivaciones" (cfr. Lukács, 1986, p. 358). En esta abstraída relación con la objetivación, la enajenación aparece como categoría ontológica distintiva del ser social y originalmente neutra. Siguiendo la asimilación y crítica de los conceptos de trabajo y de alienación (Entfremdung) que desarrollara Hegel, particularmente en la Fenomenología del Espíritu, Lukács entiende que el proceso de enajenación de la subjetividad individual en el trabajo involucra, junto a la transformación interior de las facultades y potencialidades subjetivas, la reapropiación efectiva de aquellas en una personalidad individual íntegramente desarrollada.

Tanto para Lukács como para Marx, si bien el trabajo en el capitalismo desarrolla las facultades intelectuales, emocionales y físicas de los sujetos, al mismo tiempo desarraiga al individuo de aquellas, impulsando solamente las cualidades fragmentarias y altamente especializadas que corresponden a la parcela de la división del trabajo en la que cada trabajador se desenvuelve. Hegel había postulado la superación de la distanciación entre el sujeto y las potencialidades que nacen en y con el trabajo de manera conceptual, en un momento superior a aquél en que se mueven los fenómenos característicos del trabajo social, en el plano del Espíritu Absoluto; Marx y Lukács criticaron una tal superación como abstracta y, finalmente, ficticia. Para Lukács el verdadero despliegue y cumplimiento de la enajenación conlleva la re-apropiación de las facultades y potencialidades humanas en un proceso que se orienta al desarrollo de una personalidad completa, por el cual se aplican las cualidades subjetivas en su conjunto al cultivo del hombre individual entero. La falta de aquella re-apropiación en el individuo, es decir, la falta de una actualización por parte del sujeto de sus capacidades humanas en las diferentes facetas de su accionar, es designada con el nombre de alienación (Entfremdung) ${ }^{6}$. En el capitalismo contemporáneo, la alienación, entendida como la falta de reapropiación en diversos grados y modos, es una característica común de todas las actividades económico-sociales, resultado tanto de la división social del trabajo como de la fetichización de la mercancía. Como parte de la investigación sobre las cuestiones vinculadas con la alienación de la subjetividad, aparece en Ontología del Ser Social el fenómeno social de cosificación. Las diferentes instancias que, en esta obra, ponen en primer lugar al problema de la cosificación, se corresponden estrechamente con el análisis fenomenológico de los efectos en la subjetividad de los sujetos de la fetichización de la mercancía (cfr. Lukács, 1986, p. 125ss., p. 219 , p. 227, p. 302) ${ }^{7}$. Esto está en conexión con lo que Lukács en la Ontología

\footnotetext{
${ }^{6}$ Coincidimos con Fortes cuando afirma que la posibilidad de la ausencia de re-apropiación se halla dada por la desigualdad que existe entre el desarrollo del proceso de objetivación social y el proceso por el cual el individuo transforma su propia subjetividad (cfr. Fortes, 2012, p. 76).

${ }^{7}$ No concordamos, en este sentido, con la apreciación de Tertulian (1993) y Antunes (2012) de que en
} 
del Ser Social califica como la "disolución/resolución" (Auflösung) de las categorías ontológicas mediante estudios históricos y de detalle; así afirma:

Cuando tratamos de determinar los principios de construcción teórica [...], podemos decir que tomamos como punto de partida un elevado nivel de abstracción, a partir del cual, a través de la disolución de las abstracciones metodológicamente concebidas, se construye el camino hacia la captación conceptual de la totalidad en su clara y enriquecida concreción (Lukács, 1984, p. 584).

En el proceso de, por un lado, consideración aislada (isolierte Betrachtung) del fenómeno del trabajo, y por otro, de la disolución/resolución (Auflösung) del fenómeno abstraído partiendo del descubrimiento progresivo de las relaciones que aquél establece con los diferentes planos de la realidad, es donde se ubica la caracterización que Lukács hace en Ontología del Ser Social de la génesis del trabajo. En principio, el nivel de la investigación de los caracteres distintivos del trabajo se mantiene en el rango correspondiente a las categorías ontológicas que distinguen al ser social, lo cual permite encontrar una estructura básica que se encuentra sustentada en una abstraída y por ello general estructura de la actividad social productiva. En la parte avanzada y conclusiva de Ontología del Ser Social, concretamente en el capítulo dedicado a la alienación (Entfremdung) (cfr. Lukács, 1986, pp. 501-730), se discute la disolución concreta de las abstracciones de la forma general del trabajo hasta llegar a alcanzar el complejo problemático del ser social que está más próximo a lo que la conciencia individual experimenta en la vida cotidiana (cfr. Fortes, 2012, p. 68). En ese momento, la investigación de Lukács avanza sobre los caracteres que debería tener una fenomenología de la conciencia histórica, en el marco creado por la alienación de la subjetividad que es propia del capitalismo. El capítulo de Ontología del Ser Social dedicado a la alienación (Entfremdung) avanza ampliamente sobre las categorías generales que formarían parte de una tal investigación, tomando como referente a las categorías ontológicamente consideradas de trabajo, objetivación y enajenación.

Si la alienación puede entenderse como una posibilidad permitida históricamente por la desigualdad existente entre el proceso de objetivación social y la enajenación de la subjetividad, la noción de cosificación permite entender características básicas de la relación inmediata entre la conciencia alienada —es decir, carente de real reapropiación-y el mundo social. Para una tal conciencia, las relaciones sociales aparecen como "cosas" dadas e independientes de las intenciones y transformaciones posibles de la subjetividad, e incluso la conciencia, como parte de aquella relación, se aparece a sí misma enclaustrada en determinaciones fijas. El punto de partida de esta posibilidad estriba en el

Ontología del Ser Social se plantearía la existencia de unas "cosificaciones inocentes" fundamentalmente diferentes a las "cosificaciones alienadas"; pues en todo momento aparecen, mediando la comprensión del fenómeno social de cosificación, las distintas consecuencias deformadoras de la fetichización. 
hecho de que, en el nivel de la experiencia de la vida cotidiana, los objetos naturales exteriores con los que la conciencia tiene una relación inmediata se manifiestan con el carácter de "coseidad" (Dinghaftigkeit) (cfr. Lukács, 1986, p. 477). En una fase primitiva del conocimiento todos los objetos se presentan con determinaciones que refieren al carácter de cosas, aun aquellos fenómenos que captados por la conciencia no pueden ser identificados como realidades materiales concretas (por ejemplo, una idea aprendida abstractamente, una relación social, un principio ético). Si bien el discurrir del pensamiento lleva a la superación de aquella consideración abstracta e inmediata de los contenidos de experiencia, una característica particular de la realidad social contemporánea es que la conciencia del individuo se ve puesta en relaciones que sostienen la apariencia de "cosa hecha" de los fenómenos. Como resultado de la influencia de la fetichización de la mercancía en los procesos económicos, por la cual se tiende a resaltar en los objetos — de forma abstracta y ahistórica — aquellas de sus determinaciones que son de mayor operatividad en el proceso de producción y de intercambio, los individuos consideran a toda su realidad social por intermedio de determinaciones económicas abstractas, bajo la forma de cosas hechas. En la medida en que esta es una tendencia subjetiva que no se corresponde con la verdadera naturaleza procesual de los fenómenos sociales, es posible identificarla como una expresión de la incapacidad del sujeto para re-apropiarse de sus capacidades y facultades en la forma de una personalidad integral; lo cual le impide expresar las potencialidades de la "genericidad" (Gattungsmäßigkeit) humana que, de acuerdo con el marxismo, es creada con el desarrollo de las fuerzas productivas en el transcurso de la historia. La alienación de la subjetividad que se detiene en el carácter de coseidad de los objetos descubre fenomenológicamente la influencia del fetiche de la mercancía en la dinámica de las relaciones sociales, por lo cual el concepto de cosificación siempre señalará a las relaciones sociales que promueven una tal apariencia. Esta es la razón para que Lukács tienda a utilizar el concepto de cosificación en conexión con la categoría de fetichización, en el contexto de relaciones sociales alienantes y cosificatorias. En Historia y Consciencia de Clase la distinción entre objetivación, alienación y cosificación no está aclarada, pues faltaba la conexión de los análisis fenomenológicos de las figuras de la conciencia en el capitalismo con las categorías ontológicas del ser social. Sin embargo, puede afirmarse que la categoría de cosificación de Historia y Consciencia de Clase, en la medida en que muestra la tendencia a fijarse en el carácter de coseidad de los objetos, se encuadra en el esquema planteado para la aparición de la cosificación en la Ontología del Ser Social. Los avances fenomenológicos sobre las manifestaciones concretas que toma la cosificación en el capitalismo avanzado - presentes en el capítulo dedicado a la alienación (cfr. Lukács, 1986, pp. 656-730)— recuerdan efectivamente los análisis sobre las consecuencias de la fetichización en Historia y Consciencia de Clase. De ello se puede señalar que la perspectiva fenomenológica es un paso básico para el correcto tratamiento ontológico de las categorías fundamentales del ser social 
y del trabajo, y que la argumentación ontológica ya se halla "presuponiendo" resultados de una investigación fenomenológica, además que los completa.

La investigación fenomenológica muestra que, dado que son las categorías económico-sociales las que impulsan la dinámica de la estructuración de lo social — hecho que en la Ontología del Ser Social se explica por el carácter modélico del proceso primitivo del trabajo para el despliegue y la realización de las distintas formas de objetividad-, el esquema que es adoptado en el modo de producción se extiende siempre hacia las otras diferentes facetas del todo social. Esto significa que el fetiche de la mercancía, un fenómeno que tiene su génesis en momentos puramente económicos y que alcanza su mayor concreción en el capitalismo avanzado, se extiende a las distintas relaciones interpersonales y consolida la apariencia cosificada de las categorías y los hechos sociales que parten de aquellas relaciones. Los sujetos se relacionan entre ellos con el fetiche de la mercancía como mediación, del mismo modo que todas las objetividades sociales son consideradas según determinaciones que corresponden al proceso de producción e intercambio de mercancías, lo cual tiene como resultado, según Lukács, que los sujetos y los hechos sociales objetivos no son ya considerados como esencialidades con cambiante movilidad histórica, sino como productos acabados, como hechos estáticos y definitivos en donde resaltan determinaciones económicas que se imponen a la conciencia como lo esencial. Se produce una relación fragmentaria entre los diferentes individuos que forman parte de la sociedad, y entre estos individuos y el conjunto todo social; como resultado de esta relación fragmentaria consigo mismo y con la sociedad — muestra de la carencia de una reapropiación íntegra de la individualidad - los objetos de la experiencia resaltan siempre su carácter de coseidad, ya se trate de los otros hombres o los distintos fenómenos sociales. La cosificación se transforma entonces en una estancia que atraviesa la relación del individuo con las potencialidades y posibilidades que emergen en el devenir de la esencia genérica humana y la estructuración del proceso de objetivación histórica de aquella esencia. La cosificación se transforma en una instancia natural que la conciencia de los individuos recibe y frente a la que estos se comportan. En el horizonte subjetivo de Historia y Consciencia de Clase, que busca mostrar la figura de la conciencia que corresponde al capitalismo avanzado, Lukács pudo afirmar que la cosificación es la forma fenoménica de la sociedad capitalista para todos los grupos sociales que desenvuelven su vida en esta.

La investigación sobre tal influencia de la cosificación conduce al análisis de la división del trabajo capitalista que fenomenológicamente Lukács ha llevado a cabo en Historia y Consciencia de Clase, así como en el apartado de Ontología del Ser Social dedicado a la alienación (Entfremdung). En todo el proceso del trabajo se reproduce una división que caracteriza al modo de producción capitalista. Los individuos en cada parcela de la división del trabajo, al relacionarse con los otros hombres y la realidad social, resaltan las determinaciones correspondientes 
a su posición aislada y las toman como hechos definitivos, con lo cual se consolida la parcialización de la experiencia subjetiva y la manifestación, tras los diferentes fenómenos sociales, de determinaciones abstractas con una aparente universalidad. Uno de los puntos centrales de la argumentación fenomenológica lukácsiana es que la relación fragmentaria y alienada del trabajador con el todo y con el producto de su trabajo se produce inicialmente en el ámbito del trabajo manual transformador de la naturaleza, y que el predomino de la forma de la mercancía extiende estos efectos al trabajo intelectual. Lukács analiza los efectos de un tal estado de cosas propio del trabajo intelectual en los pasajes que se ocupan de la burocracia característica del capitalismo. Estos análisis muestran que la consciencia individual reproduce, en su propia esfera de acción y pensar, las consecuencias del predominio de la forma de la mercancía como instancia de mediación entre realidad y conciencia que se efectiviza para toda actividad. Investigar la condición de este estado de cosas requiere mencionar los efectos de la racionalización, de la hiper-especialización profesional, de la ramificación de la actividad intelectual, de la orientación hacia lo mesurable y lo cuantificable de las ciencias humanas, entre otros, que son característicos fenómenos del capitalismo tardío. En escritos de crítica literaria y sociología de la literatura, Lukács analizó algunos de los efectos que una conciencia sometida a la influencia de la fetichización de la mercancía tiene para la realización de los productos intelectuales humanos, pero no llegó a constituir un cuadro de las características de la conciencia alienada en el ámbito intelectual como tema específico. La fenomenología de la conciencia en el ámbito del trabajo intelectual requiere un complejo conjunto de análisis histórico-sociales; para nuestro tema es suficiente ubicarnos en esta pregunta: ¿qué significa para el trabajo intelectual la influencia de las relaciones sociales alienantes? Para contestarla podemos recordar que, de acuerdo con Lukács, las categorías que integran el Ser Social son todas históricas y procesuales, y que en cada momento histórico cambian las determinaciones y las relaciones entre las determinaciones que conforman las categorías. Para Lukács no existen ni el trabajo — con sus distintas categorías— ni el trabajo intelectual como tales, estas siempre tendrán una determinada concreción histórica; y en rigor, la configuración actual fenoménica e inmediata de las categorías sociales es una contingencia histórica que puede cambiar en otro momento de la historia. Esta naturaleza de las categorías revela la necesidad lukácsiana de poner en claro las condiciones concretas — sujetas siempre al devenir de las formaciones económicas - en que se articula la relación de la conciencia por el mundo que es mediada por las categorías sociales como el trabajo y, así mismo, la necesidad de mostrar la forma aparencial que para el sujeto alienado toma esta relación. Especificación que torna posible precisar el horizonte conceptual de la pregunta anteriormente postulada: ¿qué significa un trabajo intelectual que se efectiviza con el predominio "inmediato" (en la superficie), pero contingente, de la influencia del fetiche de la mercancía para todo el proceso social? En principio puede afirmarse que en el sistema lukácsiano toda actividad intelectual implica la mediación de 
determinaciones correspondientes a las categorías predominantes en la lógica productiva del capitalismo - por ejemplo, de aquellas que Lukács identificaba en su análisis de la actividad intelectual que llevó a cabo en Historia y Consciencia de Clase- Existe una peculiar relación de la conciencia con la realidad objetiva que consiste en llevar al plano de la actividad intelectual determinaciones que conforman la vida cotidiana transida por el fenómeno de las relaciones sociales alienantes y cosificatorias. De esta constatación nacen algunas cuestiones centrales que examinaremos.

La conciencia tiene varias instancias de relación con la realidad objetiva, que van desde la relación más inmediata propia de la actividad económica de la vida cotidiana, hasta una relación en la que intervienen numerosas mediciones metodológicas y teóricas como es el conocimiento científico, particularmente en el caso de la ciencia de la crítica económica tal como fuera practicada por Marx en El Capital. Pero en el campo de la misma vida cotidiana se pueden distinguir instancias que corresponden a la relación más directa con la lógica de la producción y reproducción económicas, de aquellas que corresponden a la relación con los otros complejos objetivos de la vida que superan y rebasan lo económico. En el primer caso se identifica la relación inmediata, fragmentaria y parcial de la conciencia individual con las determinaciones de las categorías económicas, de tal modo que su percepción de los asuntos económicos se deja conducir por la apariencia fenoménica de las determinaciones. En el segundo caso se llega al reconocimiento de que existe un amplio campo de relaciones con las realidades objetivas que toman forma en variadas instancias de la vida ordinaria de los hombres y que superan lo económico. A este campo Lukács se refirió cuando, por ejemplo, en su crítica literaria de autores modernistas que enfatizaban la vaciedad de la vida cotidiana, resaltaba él en cambio la complejidad y variedad de las determinaciones de la vida cotidiana y del decurso vital de cada individuo. En la Ontología del Ser Social algunas de estas instancias son mostradas con abundancia descriptiva. Aquí notaremos el hecho de que, según Lukács, si bien es cierto que el hombre puede tener conciencia invertida de las categorías con las que se relaciona inmediatamente en el ejercicio del proceso económico, los otros complejos objetivos del mundo de la vida de los sujetos (la familia, la eticidad, el derecho, etcétera) permiten en potencia una cosmovisión más amplia y más compleja que la que se ve favorecida por los efectos deformadores del predominio económico del fetiche de la mercancía. Este nivel fértil y complejo de relaciones de la conciencia con las objetividades sociales se efectiviza en el curso de la vida cotidiana de los individuos. Partiendo de esta base de la vida cotidiana, la actividad intelectual puede proceder a elaborar las determinaciones del mundo de la vida de los sujetos de una forma que sepa resaltar un tipo más liberalizador de relación de la conciencia con el objeto; una tal elaboración encontramos, por ejemplo, en la actividad intelectual de los grandes artistas. 
La relación entre una Fenomenología de la conciencia moderna en el capitalismo avanzado y una Ontología del ser social permite a Lukács encuadrar la naturaleza y la realización histórica de las categorías definitorias del ser social. Posibilita, además, mostrar la manera como la categoría ontológica del trabajo adquiere características fetichizantes debido a una particular relación de la conciencia moderna con el objeto que es propia del modo de producción capitalista. Pero al mostrar la fetichización como el resultado de un análisis fenomenológico, es decir, como resultado de un análisis de las formas de la conciencia moderna, muestra la contingencia de la fetichización: la categoría ontológica del trabajo puede realizarse en otras formas de relación conciencia-objeto que son diferentes de aquellas que descubre el particular análisis fenomenológico de la conciencia en el capitalismo avanzado - tal como existió en sociedades antiguas, o como puede existir en el futuro-, así mismo muestra que existen espacios, como del trabajo intelectual en el arte, donde la conciencia puede rebasar los condicionantes que la fetichización pone a la conciencia.

\section{Referencias}

Antunes, R. (2012). Los ejercicios de la subjetividad. Las cosificaciones inocentes y las cosificaciones alienadas. En A. Infranca y M. Vedda (comps.), La alienación: historia y actualidad. Buenos Aires: Herramienta.

Benseler, F. (1986). Nachwort des Herausgebers. En G. Lukács, Zur Ontologie des gesellschaftlichen Seins. Darmstad y Neuwied: Luchterhand.

Breines, P. (1979). Young Lukács, Old Lukács, New Lukács. The Journal of Modern History, 51(3), 533-546.

Fortes, R. (2012). Las categorías de objetivación (Vergegenständlichung), enajenación (Entäuserung) y alienación (Entfremdung) en el último Lukács. En A. Infranca y M. Vedda (comps.), La alienación: historia y actualidad. Buenos Aires: Herramienta.

Infranca, A. (2005). Trabajo, Individuo, Historia. El concepto de Trabajo en Lukács. Buenos Aires: Herramienta.

Infranca, A. (2007). Fenomenología y Ontología en el Marxismo de Lukács. En A. Infranca y M. Vedda (eds.), Gÿorgy Lukács: Ética, Estética y Ontología. Buenos Aires: Colihue.

Lukács, G. (1968). Georg Lukacs Werke: Frühschriften II. Darmstad-Neuwied: Luchterhand. 
Lukács, G. (1984). Zur Ontologie des gesellschaftlichen Seins, (v.1). DarmstadNeuwied: Luchterhand.

Lukács, G. (1986). Zur Ontologie des gesellschaftlichen Seins, (v.2). DarmstadNeuwied: Luchterhand.

Marx, K. (1962). Das Kapital I. Berlin: Dietz.

Marx, K. (1968). Ökonomisch-philosophische Manuskripte aus dem Jahre 1844. Berlin: Dietz.

Marx, K. (1971). Einleitung zur Kritik der politischen Ökonomie. Berlin: Dietz.

Mészáros, I. (2009). A teoria da elienação em Marx. São Paulo: Boitempo.

Tertulian, N. (1993). Le Concept d'alienation chez Heidegger et Lukács. Archives de Philosophie. Recherches et Documentation, 56.

Zoltai, D. (1993). The Reconstructible Chief Work: Notes on Lukács Late Aesthetic Syntesis. En L. Illés y F. József (eds.), Hungarian Studies on Lukács. Budapest: Akadémiai Kiadó. 